\title{
Geschichte \\ der Griechischen Literatur
}

\author{
Von \\ Dr. Wilhelm Nestle \\ Oberstudiendirektor i. R. am Karlsgymnasium in Stuttgant \\ Honorarprofessor an der Universität in Tübingen \\ I \\ Von den Anfängen bis auf \\ Alexander d. Gr. \\ Zweite, verbesserte Auflage \\ Neudruck
}



W a l t e r d e G r u y t e r \& C. o. vormals G. J. Göschen'sche Verlagshandlung . J. Guttentag, Verlagsbuchhandlung . Georg Reimer. Karl J. Trübner. Veit \& Comp.

$$
\text { Berlin } 1950
$$


Alle Rechte, insbesonderedas Übersètzungsrecht von der Verlagshandlung vorbehalten

Archiv-Nr. 110070

Druck von Walter de Gruyter \& Co., Berlin W 35 